\title{
Blood Flow Dependence of Postglomerular Fluid Transfer and Glomerulotubular Balance
}

\author{
Valentina Kon, Mary L. Hughes, and Iekuni Ichikawa, Laboratory of Renal \\ Physiology, The Children's Hospital and Laboratory of Kidney and \\ Electrolyte Physiology, Brigham and Women's Hospital, Harvard Medical \\ School, Boston, Massachusetts 02115
}

A B S T R A C T The rate of blood flow entering a capillary network can, in some vascular systems, regulate capillary surface area and the rate of fluid and solute transfer. To determine whether such a mechanism exists in the renal peritubular capillary, we performed micropuncture studies in 28 rats during relatively low and high efferent arteriolar blood flow (EABF). High $\mathrm{EABF}$ was achieved by intravenous infusion of isoncotic plasma (group 1: from $120 \pm 11$ to $301 \pm 49 \mathrm{nl} / \mathrm{min}$ [ \pm SE]); whole blood with high hematocrit $(\sim 75$ vol \%) (group 2: from $141 \pm 14$ to $252 \pm 31 \mathrm{nl} / \mathrm{min}$ ); or acetylcholine (group 3: from $193 \pm 20$ to $266 \pm 26 \mathrm{nl} / \mathrm{min}$ ). In group 1 rats, plasma infusion caused an increase in single nephron glomerular filtration rate (SNGFR), on average, from $23.2 \pm 2.4$ to $45.2 \pm 3.9 \mathrm{nl} / \mathrm{min}$, owing primarily to increased glomerular plasma flow rate (from $63 \pm 5$ to $210 \pm 21 \mathrm{nl} / \mathrm{min}$ ). The rate of fluid uptake by the peritubular capillary, assessed by the absolute rate of proximal fluid reabsorption (APR), also rose significantly, on average from $10.5 \pm 1.2$ to $17.5 \pm 2.4$ $\mathrm{nl} / \mathrm{min}$. This rise in APR was associated with near constancy in mean transcapillary hydraulic $\left(\overline{\Delta \mathrm{P}}_{\mathrm{C}}\right)$ and oncotic $\left(\overline{\Delta \Pi}_{\mathrm{C}}\right)$ pressure differences, and was therefore attributed to a significant increase in peritubular capillary reabsorption coefficient $\left(K_{\mathrm{r}}\right)$, with the mean from $0.017 \pm 0.003$ to $0.030 \pm 0.005 \mathrm{nl} /(\mathrm{s} \cdot \mathrm{mmHg})$. In group 2 rats, high hematocrit blood infusion led to a significant rise in APR; on average, from $10.7 \pm 0.7$ to $15.0 \pm 1.2$ $\mathrm{nl} / \mathrm{min}$, without changing SNGFR. This rise in APR occurred despite unfavorable changes in the physical

Portions of these studies were presented at the Annual Meeting of the Federations of American Societies for Experimental Biology and published in abstract form in 1983. Kidney Int. 23:260a. (Abstr.); Fed. Proc. 42:1090a. (Abstr.)

Dr. V. Kon is a recipient of the American Heart Association Clinician Scientist Award.

Received for publication 17 May 1983 and in revised form 6 July 1983. forces, namely a significant increase in $\overline{\Delta \mathrm{P}}_{\mathrm{C}}$ and constancy in $\overline{\Delta \Pi}_{C}$. Instead, an increase in $\mathrm{EABF}$ was again associated with a significant rise in $K_{\mathrm{r}}$ (on average, from $0.016 \pm 0.002$ to $0.030 \pm 0.06 \mathrm{nl} /[\mathrm{s} \cdot \mathrm{mmHg}])$, which accounted entirely for the rise in APR, independently of SNGFR. In group 3 rats, in which an increase of EABF was induced pharmacologically with acetylcholine, a rise in EABF was also accompanied by a significant increase in $K_{\mathrm{r}}$, on average, from $0.019 \pm 0.002$ to $0.026 \pm 0.004 \mathrm{nl} /(\mathrm{s} \cdot \mathrm{mmHg})$. The results indicate that: (a) $K_{\mathrm{r}}$ is modulated by EABF. (b) In view of plasma flow dependence of GFR, blood flow dependence of $K_{\mathrm{r}}$ and APR provides an important basis for glomerulotubular balance.

\section{INTRODUCTION}

Previous investigators have shown under a variety of experimental conditions that changes in absolute proximal fluid reabsorption rate (APR) occur in a manner predictable from simultaneously measured levels of peritubular intracapillary oncotic and hydraulic forces (1-19). Thus, reduction in the concentration of postglomerular plasma protein, induced by a variety of experimental maneuvers, such as intravenous infusion of large volume of colloid-free solutions, was associated with a decrease in APR $(4,8)$. Conversely, systemic or direct intraperitubular capillary infusion of hyperoncotic solutions was shown to accompany a rise in APR $(4,13,18)$. In other studies, intracapillary hydraulic pressure, a force opposing peritubular capillary uptake of APR, has also been demonstrated to be an important modulator of APR $(1,3,12,15)$. However, under certain other circumstances, particularly when renal blood flow changes, the prevailing APR is not readily explainable solely on the basis of these intracapillary forces $(20-$ 27). A comparison of measurements in hydropenic and plasma-expanded rats illustrates this point: high levels 
of APR were seen in plasma-expanded rats despite levels of peritubular capillary forces that are unfavorable for avid fluid reabsorption, i.e., low oncotic or high hydraulic pressure $(5,15)$. Likewise, vasodilating substances, such as acetylcholine chloride $(\mathrm{ACH})$ and secretin, have been shown to cause no change in APR, despite low intracapillary oncotic and high hydraulic pressure (22-24). Furthermore, in recent experiments (27), rats with congestive heart failure were characterized by a high filtration fraction (hence, high postglomerular oncotic pressure) and elevated fractional proximal reabsorption, yet APR was essentially at the same level as that of normal control rats. Under such circumstances, alternative explanations for the prevailing level of fluid reabsorption must exist in the other determinants of APR. These include alterations in interstitial oncotic and hydraulic pressures, and in the peritubular capillary reabsorption coefficient $\left(K_{\mathrm{r}}\right)$.

Therefore, to ascertain the nature of the adjustments occurring in the process of peritubular capillary fluid transfer during variations in renal blood flow, we evaluated all the factors determining uptake of APR during alterations in blood flow experimentally induced by three different maneuvers. Since glomerular hemodynamics dictate, to an important extent, the forces affecting downstream peritubular capillary fluid uptake, such as via filtration fraction, we simultaneously evaluated glomerular dynamics in this study.

\section{GLOSSARY}

\begin{tabular}{|c|c|}
\hline $\mathrm{ACH}$ & acetylcholine chloride \\
\hline$\overline{\mathrm{AP}}$ & mean systemic arterial pressure, $\mathrm{mmHg}$ \\
\hline APR & $\begin{array}{l}\text { absolute proximal fluid reabsorption rate, } n l / \\
\text { min }\end{array}$ \\
\hline $\mathrm{C}$ & protein concentration, $g / d l$ \\
\hline EABF & efferent arteriolar blood flow rate, $\mathrm{nl} / \mathrm{min}$ \\
\hline GBF & glomerular blood flow rate, $\mathrm{nl} / \mathrm{min}$ \\
\hline GFR & glomerular filtration rate, $\mathrm{ml} / \mathrm{min}$ \\
\hline Het & blood hematocrit in femoral artery, vol \% \\
\hline$K_{f}$ & $\begin{array}{l}\text { glomerular capillary ultrafiltration coefficient, } \\
n l /(s \cdot m m H g)\end{array}$ \\
\hline$K_{r}$ & $\begin{array}{l}\text { peritubular capillary reabsorption coefficient, } \\
n l /(s \cdot m m H g)\end{array}$ \\
\hline $\mathbf{P}$ & hydraulic pressure, $\mathrm{mmHg}$ \\
\hline $\mathbf{P}_{\mathbf{r}}$ & $\begin{array}{l}\text { net peritubular capillary reabsorptive pressure, } \\
\mathrm{mmHg}\end{array}$ \\
\hline$P_{U F}$ & $\begin{array}{l}\text { net glomerular capillary ultrafiltration pressure, } \\
\mathrm{mmHg}\end{array}$ \\
\hline$\Delta \mathbf{P}$ & $\begin{array}{l}\text { glomerular }\left(\Delta \mathrm{P}_{\mathrm{GC}}\right) \text { or peritubular }\left(\Delta \mathrm{P}_{\mathrm{C}}\right) \\
\text { transcapillary hydraulic pressure difference } \\
\left(\Delta \mathrm{P}_{\mathrm{GC}}=\mathrm{P}_{\mathrm{GC}}-\mathrm{P}_{\mathrm{T}} ; \Delta \mathrm{P}_{\mathrm{C}}=\mathrm{P}_{\mathrm{C}}-\mathrm{P}_{\mathrm{l}}\right), m m \mathrm{mg}\end{array}$ \\
\hline$\Pi$ & oncotic pressure, $\mathrm{mm} \mathrm{Hg}$ \\
\hline$\Delta \Pi$ & $\begin{array}{l}\text { glomerular }\left(\Delta \Pi_{\mathrm{GC}}\right) \text { or peritubular }\left(\Delta \Pi_{\mathrm{C}}\right) \\
\text { transcapillary oncotic pressure difference } \\
\left(\Delta \Pi_{\mathrm{CC}} \simeq \Pi_{\mathrm{GC}} ; \Delta \Pi_{\mathrm{C}}=\Pi_{\mathrm{C}}-\Pi_{1}\right), \mathrm{mmHg}\end{array}$ \\
\hline $\mathbf{Q}$ & plasma flow rate, $\mathrm{nl} / \mathrm{min}$ \\
\hline & resistance to blood flow, $\times 10^{10} \mathrm{dyn} \cdot \mathrm{s} \cdot \mathrm{cm}^{-5}$ \\
\hline $\begin{array}{l}\text { SNFF } \\
\text { SNGFR }\end{array}$ & $\begin{array}{l}\text { single nephron filtration fraction } \\
\text { single nephron GFR, } n l / \min \end{array}$ \\
\hline
\end{tabular}

$(\mathrm{TF} / \mathrm{P})_{\text {In }}$ late proximal tubule fluid-to-plasma inulin
concentration ratio

$\mathrm{V}_{\mathrm{TF}} \quad$ late proximal tubule fluid flow rate, $\mathrm{nl} / \mathrm{min}$

\section{Superscript}

- mean value

\section{Subscripts}

$\begin{array}{ll}\text { A } & \text { afferent arteriole } \\ \text { C } & \text { peritubular capillary } \\ \text { C } & \text { distalmost peritubular capillary } \\ \text { E } & \text { efferent arteriole (i.e., proximalmost peritubular } \\ & \text { capillary) } \\ \text { GC } & \text { glomerular capillary } \\ \text { I } & \text { cortical interstitium } \\ \text { T } & \text { proximal tubule }\end{array}$

\section{METHODS}

\section{Animal preparation and specific measurements}

Studies were performed in adult male Munich-Wistar rats, weighing 223-309 g. All rats were allowed free access to tap water and standard rat chow until the day of the experiment. The animals were anesthetized with Inactin $(100 \mathrm{mg} / \mathrm{kg}$, i.p.) and placed on a temperature-regulated micropuncture table. Each animal underwent a tracheostomy. Indwelling polyethylene catheters were inserted into the right and left jugular veins for infusions of inulin and isoncotic rat plasma. The left femoral artery was catheterized for periodic sampling of blood and recording of mean systemic arterial blood pressure (AP). AP was monitored with an electronic transducer (model P-23Db, Statham Instruments Div., Gould, Inc., Oxnard, CA) connected to a direct writing recorder (model 2200, Gould, Inc.). The left kidney was exposed by ventral midline and subcostal incisions, suspended on a Lucite holder, its surface illuminated with a fiberoptic light source, and bathed with $0.9 \% \mathrm{NaCl}$ heated to $35^{\circ}-37^{\circ} \mathrm{C}$.

In all experiments, micropuncture measurements and collections were carried out as follows. Timed (1-2 min) samples of fluid were collected from surface late proximal convolutions from each of one to three nephrons for determintion of flow rate, inulin concentration, and calculation of tubule fluid-to-plasma inulin concentration ratio, $(\mathrm{TF} / \mathrm{P})_{\mathrm{In}}$, hence, single nephron glomerular filtration rate (SNGFR) and APR. These late surface convolutions of proximal tubules were located by observing the passage of lissamine green dye that was injected rapidly $(0.05 \mathrm{ml}$ of a $5 \%$ solution) into the right jugular vein catheter. The rate of fluid collection was adjusted to maintain a column of polymer oil three to four tubule diameters in length in a constant position just distal to the site of puncture. Coincident with the tubule fluid collection, femoral arterial blood samples were obtained for determination of hematocrit (Hct) and plasma inulin and protein concentrations.

Hydraulic pressures were monitored in accessible surface structures with a continuous recording, servo-null micropipette transducer system (model 3, Instrumentation for Physiology and Medicine, Inc., San Diego, CA). Micropipettes with an outer tip diameter of $1-2 \mu \mathrm{m}$ containing $2.0 \mathrm{M} \mathrm{NaCl}$ were used. Hydraulic output from the servo-null system was coupled electronically to a second channel of a Gould recorder by means of a pressure transducer. Direct measure- 
ments of time-averaged hydraulic pressures were recorded in single capillaries of surface glomeruli $\left(\overline{\mathrm{P}}_{\mathrm{GC}}\right)$, proximal tubules $\left(\mathrm{P}_{\mathrm{T}}\right)$, efferent arterioles $\left(\mathrm{P}_{\mathrm{E}}\right)$, and distalmost branches of the peritubular capillaries $\left(\mathrm{P}_{\mathrm{C}^{1}}\right)$. By the same device, subcapsular space hydraulic pressure was also measured and values taken to represent cortical interstitial hydraulic pressure $\left(\mathrm{P}_{1}\right)$ as described in detail previously $(1,2,20)$.

Protein concentrations of plasma entering glomerular $\left(C_{A}\right)$ and peritubular capillaries $\left(C_{E}\right)$ were determined by analyzing femoral arterial and surface efferent arteriolar blood plasmas, respectively. These inlet estimates of pre- and postglomerular plasma protein concentration also permit calculation of single nephron filtration fraction (SNFF) and initial glomerular $\left(Q_{A}\right)$ and peritubular $\left(Q_{E}\right)$ capillary plasma flow rates. Oncotic pressures of afferent $\left(\Pi_{\Lambda}\right)$ and efferent $\left(\Pi_{E}\right)$ arteriolar plasma were calculated from values of $C_{A}$ and $C_{E}$, respectively. Renal lymph was obtained by inserting micropipettes (outer tip diameter of $\sim 25 \mu \mathrm{m}$ ) into an intact renal hilar lymph vessel. Since renal lymph is thought to originate primarily in the cortex (28-31), interstitial oncotic pressure $\left(\Pi_{1}\right)$ was estimated from the value of protein concentration of this lymph fluid. In some animals, hilar lymph vessels were not readily accessible for lymphatic fluid collection because of excessive perirenal fat tissue. In these animals, subcapsular fluid was collected for the determination of $\Pi_{1}$ by the methods of Tucker and Blantz (3).

The volume of fluid collected from individual end-proximal tubules was estimated from the length of the fluid column in a constant-bore capillary tube of known internal diameter. The concentration of inulin in tubule fluid was measured in duplicate by the microfluorescence method of Vurek and Pegram (32). Inulin concentrations in plasma were determined by the macroanthrone method of Führ et al. (33). $\mathrm{C}_{\mathrm{A}}$ and $\mathrm{C}_{\mathrm{E}}$ were determined, usually in duplicate, by the fluorometric method of Viets et al. (34). Protein concentration in hilar lymph and subcapsular fluid was determined with an ultramicrocolorimeter, by means of a microadaptation (4) of the method of Lowry et al. (35).

\section{Experimental groups}

Group 1 ( $n=11$ rats). In this group, the effect of increased $Q_{A}$ and $Q_{E}$ on glomerular and postglomerular fluid transfer was simultaneously examined. The above described micropuncture measurements and collections were performed during hydropenia. After completion of this initial study period, each rat received an intravenous infusion of homologous rat plasma in a volume equal to $\sim 3 \%$ body wt administered over $45 \mathrm{~min}$. The infusion rate of plasma was then reduced to $1.2 \mathrm{ml} / \mathrm{h}$ for the remainder of the experiment. $30 \mathrm{~min}$ later, measurements and collections specified above were repeated. Often, recollection of late proximal tubule fluid was obtained from previous puncture sites in the same tubules studied during the initial period.

Group $2(n=10$ rats $)$. In this group, the protocol was designed to increase the peritubular capillary blood flow rate without altering glomerular filtration rate (GFR). In preliminary studies, the following protocol was found to fulfill these goals. The rats initially received $0.5 \%$ body wt infusion of homologous rat plasma in $15 \mathrm{~min}$, followed by a reduction in the infusion rate to $1.2 \mathrm{ml} / \mathrm{h}$ for the remainder of the experiment. At the completion of the initial measurements and fluid collections specified above, each rat received an intravenous infusion of blood with a high Hct in a volume equal to $\sim 2.5 \%$ body wt in $45 \mathrm{~min}$. The infused blood was prepared as follows: On the morning of the experiment, whole blood was withdrawn from litter mates into heparin- ized syringes and centrifuged at $3,500 \mathrm{rpm}$ for $20 \mathrm{~min}$. The cells were then resuspended in saline to wash away any clots, and the suspension recentrifuged. Care was taken in preparing the erythrocytes to avoid clots, clumping, or hemolysis. The cells thus prepared were mixed with plasma and $0.9 \% \mathrm{NaCl}$ solution in a ratio of $6: 1: 0.8$ to attain a final Hct of $\sim 75$ vol $\%$. After this transfusion, micropuncture measurements and collections were repeated.

Group 3 ( $n=7$ rats). In this group, we attempted to pharmacologically increase glomerular and postglomerular blood flow. The initial measurements were made in either hydropenic ( $n=3$ rats) or euvolemic conditions ( $n=4$ rats). The protocol for establishing euvolemic conditions has been detailed previously (36). During the second part, ACH (Sigma Chemical Co., St. Louis, MO) was infused intravenously at a rate of $2-3 \mu \mathrm{g} / \mathrm{min}$. After a $30-\mathrm{min}$ equilibration period, the pertinent micropuncture measurements were repeated.

\section{Calculations}

SNGFR $=(T F / P)_{\text {In }} \times V_{T F}$, where $V_{T F}$ refers to tubule fluid flow rate. According to the Starling relationship, SNGFR is given by

$$
\begin{aligned}
\text { SNGFR } & =K_{\mathrm{f}} \times \overline{\mathrm{P}}_{\mathrm{UF}} \\
& =K_{\mathrm{f}} \times\left(\overline{\Delta \mathrm{P}}_{\mathrm{GC}}-\overline{\Delta \Pi}_{\mathrm{GC}}\right),
\end{aligned}
$$

where $\overline{\mathrm{P}}_{\mathrm{UF}}$ represents mean ultrafiltration pressure and $\overline{\Delta \mathbf{P}}_{\mathrm{GC}}$ and $\overline{\Delta \Pi}_{\mathrm{GC}}$ are mean glomerular transcapillary hydraulic and oncotic pressure differences, respectively. Ultrafiltration coefficient $\left(K_{f}\right), \overline{\mathrm{P}}_{\mathrm{UF}}, \overline{\Delta \mathrm{P}}_{\mathrm{GC}}$, and $\overline{\Delta \Pi}_{\mathrm{GC}}$ were calculated from equations described in detail elsewhere as were afferent $\left(R_{A}\right)$ and efferent $\left(R_{E}\right)$ arteriolar resistances (37). SNFF is given by $\mathrm{SNFF}=1-\left(\mathrm{C}_{\mathrm{A}} / \mathrm{C}_{\mathrm{E}}\right)$. Initial glomerular plasma flow rate: $Q_{A}=S N G F R / S N F F$. Efferent arteriolar plasma flow rate: $Q_{E}=Q_{A}-S N G F R$. Blood flow rate per single afferent arteriole or glomerulus $(\mathrm{GBF})=\mathrm{Q}_{\mathbf{A}} /\left(\mathbf{l}-\mathbf{H c t}_{\mathrm{a}}\right)$, where $\mathrm{Hct}_{\mathrm{a}}$, the Hct of afferent arteriolar blood, is taken to equal femoral arterial Hct. Efferent arteriolar blood flow rate $(\mathrm{EABF})=\mathrm{GBF}-\mathrm{SNGFR}$.

Using the value of $(T F / P)_{\ln }$ and $V_{T F}$ at the late proximal tubule, APR to the end of the proximal tubule is given by: APR $=$ SNGFR $-V_{\mathrm{TF}}$. The Starling relationship applied to the peritubular capillaries predicts the rate of peritubular capillary uptake of APR to be

$$
\begin{aligned}
\mathrm{APR} & =K_{\mathrm{r}} \times \overline{\mathrm{P}}_{\mathrm{r}} \\
& =K_{\mathrm{r}} \times\left(\overline{\Delta \Pi}_{\mathrm{C}}-{\overline{\Delta \mathrm{P}_{\mathrm{C}}}}\right) \\
& =K_{\mathrm{r}} \times\left[\left(\bar{\Pi}_{\mathrm{C}}-\bar{\Pi}_{\mathrm{l}}\right)-\left(\overline{\mathrm{P}}_{\mathrm{C}}-\overline{\mathrm{P}}_{\mathrm{l}}\right)\right]
\end{aligned}
$$

where $\overline{\mathrm{P}}_{\mathrm{r}}$ represents mean net peritubular capillary reabsorptive pressure and ${\overline{\Delta \Pi_{C}}}_{C}$ and $\overline{\Delta P}_{C}$ are mean peritubular transcapillary oncotic and hydraulic pressure differences, respectively; $\bar{\Pi}_{C}$ and $\overline{\mathrm{P}}_{\mathrm{C}}$ are mean intracapillary oncotic and hydraulic pressures. $K_{\mathrm{r}}, \overline{\mathrm{P}}_{\mathrm{r}}, \overline{\Delta \mathrm{P}}_{\mathrm{C}}, \overline{\Delta \Pi}_{\mathrm{C}}, \bar{\Pi}_{\mathrm{c}}$, and $\overline{\mathrm{P}}_{\mathrm{C}}$ were calculated from the mathematical model developed by Deen et al. (38) and Blantz and Tucker (2).

In the above described calculations for various indices of glomerular and peritubular capillary hemodynamics, $\Pi$ values were estimated from the values of protein concentrations (C) with the following relationship: $\Pi=a_{1} C$ $+a_{2} C^{2}$, where $a_{1}=1.63$ and $a_{2}=0.294$ (for $4 \leqq C \leqq 10$ $\mathrm{g} / \mathrm{dl}$ ) for plasmas, assuming an albumin-to-globulin concentration ratio of 1.0 , the ratio found in normal rats by 
us and others $(5,39)$. For renal lymph, $a_{1}=1.89$ and $a_{2}$ $=0.469$ (for $0 \leqq \mathrm{C} \leqq 2 \mathrm{~g} / \mathrm{dl}$ ), assuming an albumin-toglobulin concentration ratio of 2.0 , the ratio also found in rats $(5,39)$.

Statistical analyses were performed by $t$ test where appropriate. Statistical significance was defined as $P<0.05$.

\section{RESULTS}

Group 1 (plasma infusion). Mean values of $\overline{\mathrm{AP}}$, the pertinent measurements of plasma composition and single nephron function during control period and after plasma infusion (group 1) are shown in Table I and Fig. 1. The initial measurements were conducted during hydropenia, i.e., without replacement of plasma volume lost during surgical preparation (36). Many of the measurements describing glomerular and peritubular capillary fluid exchanges have already been made by a number of investigators in Munich-Wistar rats under similar conditions $(5,22)$, and are comparable to those obtained in the present study, including the attainment of near equality between $\Pi_{E}$ and $\overline{\Delta \mathrm{P}}_{\mathrm{GC}}$, as well as comparable values for $(\mathrm{TF} / \mathrm{P})_{\mathrm{In}}$ and absolute proximal tubule reabsorption rate.

After infusion of homologous rat plasma in a volume equal to $\sim 3 \%$ body wt, $\overline{\mathrm{AP}}$ did not change significantly, averaging $103 \pm 8 \mathrm{mmHg}$ before and $110 \pm 3$ $\mathrm{mmHg}$ after plasma infusion (Table I). As expected, the Hct decreased, from an average of $55 \pm 1$ to $39 \pm 1$ vol \%. SNGFR increased in each animal (Fig. 1), on average from $23.2 \pm 2.4$ to $45.2 \pm 3.9 \mathrm{nl} / \mathrm{min}$. As shown in Table $I$, evaluation of the forces determining SNGFR revealed that $\overline{\Delta \mathrm{P}}_{\mathrm{GC}}$ was slightly elevated after plasma infusion, averaging $33.1 \pm 0.8$ vs. $34.5 \pm 0.7$ $\mathrm{mmHg}$. This increase in $\overline{\Delta \mathrm{P}}_{\mathrm{GC}}$ was associated with an elevation in both $\bar{P}_{G C}$ and $P_{T}$, as shown. Values for $C_{A}$ increased on average from $5.3 \pm 0.1$ to $6.0 \pm 0.1 \mathrm{~g} / \mathrm{dl}$ after plasma infusion. ${ }^{1}$ In response to plasma infusion, $\mathrm{Q}_{\mathrm{A}}$ increased significantly and markedly, from an average of $63 \pm 5$ to $210 \pm 21 \mathrm{nl} / \mathrm{min}$. This relatively greater increase in $Q_{A}$ than SNGFR in these animals is expressed as a significant fall in SNFF, the latter averaging $0.37 \pm 0.02$ vs. $0.23 \pm 0.02$. Lastly, $K_{f}$ rose from an average of $0.063 \pm 0.011$ to $0.100 \pm 0.012 \mathrm{nl} /$ $(\mathrm{s} \cdot \mathrm{mmHg})^{2}$

\footnotetext{
${ }^{1}$ Increase in $\mathrm{C}_{\mathrm{A}}$ has also been observed after isoncotic plasma infusion in previous studies $(14,40)$. It is speculated that this increase in systemic plasma protein concentration reflects high intracapillary hydraulic pressure in peripheral capillary during plasma volume expansion, presumably causing extravasation of colloid-free fluid.

${ }^{2}$ The value of $\Pi_{\mathrm{E}} / \overline{\Delta \mathrm{P}}_{\mathrm{CC}}$ was $<0.95$ in 3 of 11 rats during hydropenia and 7 of 11 after plasma infusion. Since $\Pi_{E} /$ $\overline{\Delta \mathrm{P}}_{\mathrm{CC}}$ averaged $\sim 1$ during hydropenia, one may infer that essentially all animals were at filtration pressure equilibrium in this period and $\Pi_{E} / \overline{\Delta P}_{G C}>1$ or $<1$ in individual animals reflected technical variation. Thus, only minimum values were calculated in hydropenia, and their average given. For $K_{\mathrm{f}}$
}

The average values for APR and the various factors determining postglomerular fluid uptake of APR were examined and the results also given in Fig. 1 and Table I. Although values for $(\mathrm{TF} / \mathrm{P})_{\mathrm{ln}}$, an index for fractional proximal fluid reabsorption, decreased (on average from $1.98 \pm 0.09$ to $1.78 \pm 0.12)$, APR increased uniformly and substantially (Fig. 1), averaging $10.5 \pm 1.2 \mathrm{nl} / \mathrm{min}$ before and $17.5 \pm 2.4 \mathrm{nl} / \mathrm{min}$ after plasma infusion. The hydraulic pressure measured at the beginning and distalmost accessible portions of the peritubular capillary, i.e., $P_{E}$ and $P_{C^{1}}$, increased with plasma infusion. Hence, the average hydraulic pressure along the peritubular capillary, $\overline{\mathrm{P}}_{\mathrm{C}}$, was $12.3 \pm 0.4 \mathrm{mmHg}$ in the base-line period and rose significantly to $14.9 \pm 0.9 \mathrm{mmHg}$ in the second period. Although numerically small, the increase in $P_{1}$ was also significant after plasma infusion, rising from an average of $0.5 \pm 0.3$ to $2.7 \pm 0.4 \mathrm{mmHg}$. As a consequence, the values for $\overline{\Delta P}_{C}$ remained essentially unchanged (mean: $11.8 \pm 0.5$ vs. $12.2 \pm 0.7 \mathrm{~mm} \mathrm{Hg}$ ) with plasma infusion. In association with the fall in glomerular filtration fraction, the oncotic pressure measured at the beginning of the peritubular capillary, $\Pi_{E}$, declined after plasma infusion, on average from $35.5 \pm 1.9$ to $30.9 \pm 1.2 \mathrm{mmHg}$. Nevertheless, values for oncotic pressure averaged over the entire length of the peritubular capillary, $\bar{\Pi}_{C}$, were virtually identical before and after plasma infusion, as shown. This near-equality in $\bar{\Pi}_{C}$ values between the two study periods is the result of increased peritubular capillary plasma flow rate, $Q_{E}$, after plasma infusion. ${ }^{3}$ The increase in $Q_{E}$ also served to increase the rate of blood flow entering the peritubular capillary, EABF, the latter averaging $120 \pm 11$ $\mathrm{nl} / \mathrm{min}$ before and $301 \pm 49 \mathrm{nl} / \mathrm{min}$ after plasma infusion. The average value for interstitial oncotic pressure, $\Pi_{1}$, was comparable between the two periods, also contributing to the near constancy in the value for $\overline{\Delta \Pi}_{C}$, $22.9 \pm 0.9 \mathrm{mmHg}$ before and $22.6 \pm 0.7 \mathrm{mmHg}$ after plasma infusion. Overall, net peritubular capillary reabsorptive pressure, $\overline{\mathrm{P}}_{\mathrm{r}}$, was unaffected by plasma infusion, i.e., averaging $11.2 \pm 0.5 \mathrm{mmHg}$ before and $10.4 \pm 0.6 \mathrm{mmHg}$ after plasma. By contrast, $K_{\mathrm{r}}$ was calculated to increase in all but one rat, averaging

values after plasma infusion, seven unique values were pooled with four minimum values in calculating the average. The achievement of filtration pressure equilibrium in many animals during hydropenia does not permit conclusions regarding the direction and magnitude of change in $K_{f}$, if any, occurring in these animals.

${ }^{3}$ The mathematical model of Deen et al. (38) predicts that the inlet value of peritubular capillary plasma flow rate determines the magnitude of dilution of plasma protein by reabsorption of colloid-free proximal tubule fluid along the peritubular capillary, hence oncotic pressure. Higher $Q$, for instance, by lessening the extent of dilution of plasma protein increases the average oncotic pressure. 
TABLE I

Summary of Whole Body, Glomerular, and Peritubular Capillary Hemodynamics in Group 1 Rats (Plasma Infusion)

\begin{tabular}{|c|c|c|c|c|c|c|c|c|c|c|c|c|}
\hline & $\overline{\mathbf{A P}}$ & Het & $\mathrm{C}_{\mathrm{A}}$ & SNGFR & $Q_{A}$ & SNFF & $\overline{\mathrm{P}}_{\mathrm{GC}}$ & $\mathbf{P}_{\mathbf{T}}$ & $\overline{\Delta \mathrm{P}}_{\mathrm{cC}}$ & $\mathbf{R}_{\mathbf{A}}$ & $\mathbf{R}_{\mathrm{E}}$ & $K_{f}$ \\
\hline & $m m H g$ & vol \% & $g / d l$ & $n l / \min$ & $n l / \min$ & & $m m H g$ & $m m H g$ & $m m H g$ & $\times 10^{10} d y$ & $\mathrm{~s} \cdot \mathrm{cm}^{-\mathrm{s}}$ & $n l /(s \cdot m m H g)$ \\
\hline \multirow[t]{2}{*}{ Before } & 103 & 55 & 5.3 & 23.2 & 63 & 0.37 & 45.9 & 12.9 & 33.1 & 3.88 & 2.20 & $>0.063$ \\
\hline & 8 & 1 & 0.1 & 2.4 & 5 & 0.02 & 0.9 & 0.4 & 0.8 & 0.35 & 0.23 & 0.011 \\
\hline \multirow[t]{2}{*}{ After } & 110 & 39 & 6.0 & 45.2 & 210 & 0.23 & 48.1 & 13.6 & 34.5 & 1.47 & 0.95 & 0.100 \\
\hline & 3 & 1 & 0.1 & 3.9 & 21 & 0.02 & 0.6 & 0.4 & 0.7 & 0.15 & 0.19 & 0.012 \\
\hline$P$ & NS & $<0.001$ & $<0.005$ & $<0.001$ & $<0.001$ & $<0.001$ & $<0.01$ & NS & $<0.05$ & $<0.001$ & $<0.001$ & NS \\
\hline
\end{tabular}

Values are expressed as means \pm 1 SE. $n=11$ rats.

$0.017 \pm 0.003 \mathrm{nl} /(\mathrm{s} \cdot \mathrm{mmHg})$ before and $0.030 \pm 0.005 \mathrm{nl} /$ $(\mathrm{s} \cdot \mathrm{mmHg})$ after plasma infusion.

Group 2. The values for SNGFR, APR, and the determinants of glomerular and peritubular capillary fluid exchanges obtained in group 2, before and after infusion of $\sim 2.5 \%$ body wt of the high Het blood are shown in Fig. 1 and Table II. The values for $\overline{\mathrm{AP}}$ averaged $103 \pm 3 \mathrm{mmHg}$ before and $112 \pm 5 \mathrm{mmHg}$ after the blood infusion. Values for systemic arterial Hct increased uniformly, on average from $48 \pm 1$ to $64 \pm 1$ vol \%. SNGFR was comparable between the two periods, averaging $27.3 \pm 1.7 \mathrm{nl} / \mathrm{min}$ during base-line con-

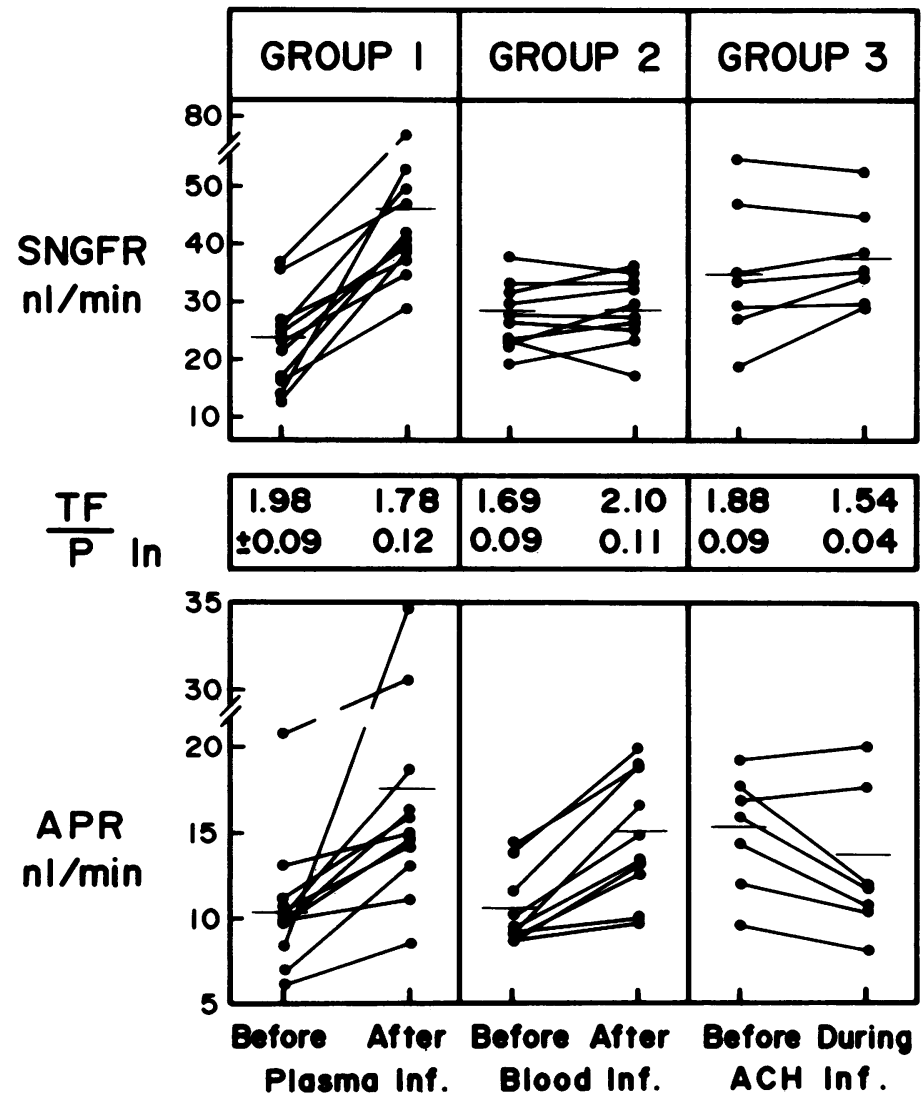

FIGURE 1 Values for SNGFR and APR measured in each animal before and after plasma infusion (group 1), high Het blood infusion (group 2), and $\mathrm{ACH}$ infusion (group 3). Average values are given as horizontal bars. Average value for $(\mathrm{TF} / \mathrm{P})_{\ln }$ for each group is also provided, and is expressed as mean $\pm 1 \mathrm{SE}$. 
TABLE I (Continued)

\begin{tabular}{|c|c|c|c|c|c|c|c|c|c|c|c|c|c|c|}
\hline$(T F / P)_{h \mathbb{m}}$ & $\mathrm{APR}$ & EABF & $Q_{\mathbf{E}}$ & $\Pi_{\varepsilon}$ & $\mathbf{\Pi}_{\mathbf{c}}$ & $\Pi_{1}$ & $\overline{\Delta \Pi}_{c}$ & $P_{E}$ & $\mathbf{P}_{\mathrm{C}^{\prime}}$ & $\overline{\mathrm{P}}_{\mathrm{c}}$ & $P_{1}$ & ${\overline{\Delta \mathrm{P}_{\mathrm{c}}}}$ & $\overline{\mathrm{P}}_{\mathrm{r}}$ & $K_{r}$ \\
\hline & $n l / m i n$ & $n l / m i n$ & $n l / m i n$ & $m m H g$ & $\mathrm{mmHg}$ & $m m H g$ & $\mathrm{mmHg}$ & $\mathrm{mmHg}$ & $m m H g$ & $m m H g$ & $m m H g$ & $m m H g$ & $\mathrm{mmHg}$ & $n l /(s \cdot m m H g)$ \\
\hline 1.98 & 10.5 & 120 & 40 & 35.5 & 27.8 & 4.9 & 22.9 & 16.1 & 8.4 & 12.3 & 0.5 & 11.8 & 11.2 & 0.017 \\
\hline 0.09 & 1.2 & 11 & 3 & 1.9 & 1.0 & 0.8 & 0.9 & 0.5 & 0.5 & 0.4 & 0.3 & 0.5 & 0.5 & 0.003 \\
\hline 1.78 & 17.5 & 301 & 165 & 30.9 & 27.7 & 5.0 & 22.6 & 18.5 & 11.2 & 14.9 & 2.7 & 12.2 & 10.4 & 0.030 \\
\hline 0.12 & 2.4 & 49 & 19 & 1.2 & 0.9 & 0.8 & 0.7 & 0.8 & 0.1 & 0.9 & 0.4 & 0.7 & 0.6 & 0.005 \\
\hline NS & $<0.01$ & $<0.005$ & $<0.001$ & $<0.025$ & NS & NS & NS & $<0.05$ & $<0.025$ & $<0.025$ & $<0.001$ & NS & NS & $<0.025$ \\
\hline
\end{tabular}

ditions and $28.5 \pm 1.9 \mathrm{nl} / \mathrm{min}$ after high Hct blood infusion. Of the various determinants of SNGFR, $\overline{\Delta P}_{\mathrm{GC}}$ failed to change significantly, averaging $32.8 \pm 0.8$ $\mathrm{mmHg}$ in the first period and $33.0 \pm 1.0 \mathrm{mmHg}$ in the second period. The constancy in $\overline{\Delta \mathrm{P}}_{\mathrm{GC}}$ reflected an absence of changes in both $\overline{\mathrm{P}}_{\mathrm{GC}}$ and $\mathrm{P}_{\mathrm{T}}$ throughout this experiment, averaging $45.4 \pm 0.8$ vs. $45.7 \pm 0.9 \mathrm{~mm} \mathrm{Hg}$ and $12.6 \pm 0.4$ vs. $12.7 \pm 0.3 \mathrm{mmHg}$, respectively. As in group 1 experiments, $C_{A}$ increased mildly and significantly after blood infusion. Values for $Q_{A}$ also increased slightly in response to blood infusion as shown in Table II. Finally, the mean values for $K_{\mathrm{f}}$ increased from an average value of $0.059 \pm 0.005$ to $0.085 \pm 0.008$ $\mathrm{nl} /(\mathrm{s} \cdot \mathrm{mmHg}){ }^{4}$

In contrast to the observed constancy in SNGFR, values for APR increased significantly from an average of $10.7 \pm 0.7$ to $15.0 \pm 1.2 \mathrm{nl} / \mathrm{min}$ after blood infusion (Fig. 1, Table II). Thus, the $(\mathrm{TF} / \mathrm{P})_{\mathrm{In}}$ also increased significantly from a mean of $1.69 \pm 0.09$ to $2.10 \pm 0.11$. The various factors determining postglomerular fluid exchange are also given in Table II. Infusion of high Hct solution caused a uniform increase in $P_{E}$ and $\mathrm{P}_{\mathrm{C}^{1}}$, yielding a significantly higher $\overline{\mathrm{P}}_{\mathrm{C}}$ in the second period (mean $12.4 \pm 0.4$ vs. $15.4 \pm 0.6 \mathrm{mmHg}$ ). Quantitatively, this increase in $\overline{\mathrm{P}}_{\mathrm{C}}$ exceeded a small but significant increase in $P_{1}$ and led to a higher value for $\overline{\Delta \mathrm{P}}_{\mathrm{C}}$ after blood infusion, the latter averaging $11.2 \pm 0.3$ $\mathrm{mmHg}$ before and $13.3 \pm 0.5 \mathrm{mmHg}$ after infusion. In contrast, $\Pi_{E}$ and $\bar{\Pi}_{C}$ remained relatively constant before and after blood infusion. Although there was a small but significant increase in $\Pi_{1}$ in the second period of these experiments (Table II), values for $\overline{\Delta \Pi}_{C}$ were comparable between the two periods, averaging $23.7 \pm 1.5$ vs. $24.1 \pm 1.6 \mathrm{mmHg}$. Owing to the increase in the level of $\overline{\Delta \mathrm{P}}_{\mathrm{C}}$ and the constancy in $\overline{\Delta \Pi}_{\mathrm{C}}$, average value for

\footnotetext{
${ }^{4}$ For reasons identical to those of group 1 hydropenic rats (footnote 2), only minimum values were calculated for both experimental periods in this group. Thus, the values given here represent average for minimum $K_{f}$ values, and conclusions regarding changes in $K_{f}$ values cannot be determined.
}

$\overline{\mathrm{P}}_{\mathrm{r}}$ was calculated to decrease numerically although this decrease did not reach statistical significance, as shown. $K_{\mathrm{r}}$ increased in all but one animal, averaging $0.016 \pm 0.002 \mathrm{nl} /(\mathrm{s} \cdot \mathrm{mmHg})$ before and $0.030 \pm 0.006 \mathrm{nl} /$ $(\mathrm{s} \cdot \mathrm{mmHg})$ after blood infusion. In association with the increased Hct of systemic blood and a very mild increase in $Q_{E}(59 \pm 8$ vs. $71 \pm 9 \mathrm{nl} / \mathrm{min}), E A B F$ increased significantly and substantially, on average from $141 \pm 14$ vs. $252 \pm 31 \mathrm{nl} / \mathrm{min}$.

Group 3. The above measurements were duplicated in group 3, before and during intravenous infusion of $\underline{A C H}$ and the results are given in Fig. 1 and Table III. AP fell slightly, on average from $106 \pm 2$ to $100 \pm 3$ $\mathrm{mmHg}$. Het was identical before and after $\mathrm{ACH}$ infusion, averaging $51 \pm 2$ vol \% for both periods. Values for SNGFR failed to change significantly $(35.0 \pm 4.5 \mathrm{vs}$. $38.0 \pm 3.1 \mathrm{nl} / \mathrm{min}) . \Delta \mathrm{P}_{\mathrm{GC}}$ increased significantly in response to $\mathrm{ACH}$ infusion, averaging $35.6 \pm 1.5 \mathrm{mmHg}$ before and $38.4 \pm 1.6 \mathrm{mmHg}$ during the infusion. These values reflect a slight increase in $\overline{\mathrm{P}}_{\mathrm{GC}}(49.2 \pm 1.4$ to $52.0 \pm 1.5 \mathrm{mmHg})$ and constancy in $\mathrm{P}_{\mathrm{T}}(13.5 \pm 1.3 \mathrm{vs}$. $13.6 \pm 0.7 \mathrm{mmHg}$ ). Whereas $C_{A}$ failed to change significantly with $\mathrm{ACH}$ infusion, $\mathrm{Q}_{\mathrm{A}}$ increased markedly and significantly, from an average of $111 \pm 17$ to $148 \pm 20$ $\mathrm{nl} / \mathrm{min}$. This rise in $Q_{A}$ with relatively constant SNGFR is expressed by a fall in the value for SNFF, which averaged $0.32 \pm 0.01$ before and $0.27 \pm 0.02$ during $\mathrm{ACH}$ infusion. Values for $K_{\mathrm{f}}$ fell on average from $0.076 \pm 0.019$ to $0.059 \pm 0.018 \mathrm{nl} /(\mathrm{s} \cdot \mathrm{mmHg}){ }^{5}$ but this change failed to reach statistical significance. Thus, the constancy in the value of SNGFR during ACH infusion occurred under the opposing influences of increases in $Q_{A}$ and $\overline{\Delta \mathrm{P}}_{\mathrm{GC}}$ vs. a decrease in $K_{\mathrm{f}}$.

In these animals, values for APR also failed to change significantly, averaging $15.4 \pm 1.3 \mathrm{nl} / \mathrm{min}$ before and

\footnotetext{
${ }^{5}$ The value for $\Pi_{E} / \overline{\Delta P}_{C C}$ was $>0.95$ in three of seven animals before $\mathrm{ACH}$ infusion, where only minimum values were calculated. These minimum values were pooled with unique values from four animals for calculation of the average. $\Pi_{E} /$ $\overline{\Delta P}_{\mathrm{GC}}$ was $<0.95$ in all of the animals during $\mathrm{ACH}$ infusion, permitting calculation of unique values for $K_{f}$ for this period.
} 
TABLE II

Summary of Whole Body, Glomerular, and Peritubular Capillary Hemodynamics in Group 2 Rats (Blood Infusion)

\begin{tabular}{|c|c|c|c|c|c|c|c|c|c|c|c|c|}
\hline & $\overline{\mathrm{AP}}$ & Het & $\mathrm{C}_{\mathrm{A}}$ & SNGFR & $Q_{A}$ & SNFF & $\overline{\mathrm{P}}_{\mathrm{CC}}$ & $\mathbf{P}_{\mathbf{T}}$ & $\overline{\Delta \mathrm{P}}_{\mathrm{GC}}$ & $\mathbf{R}_{\mathbf{A}}$ & $\mathbf{R}_{\mathrm{E}}$ & $K_{f}$ \\
\hline & $m m H g$ & vol \% & $g / d l$ & $n l / \min$ & $n l / \min$ & & $m m H g$ & $m m H g$ & $m m H g$ & $\times 10^{10} \mathrm{~d}$ & $s \cdot \mathrm{cm}^{-s}$ & $n l /(s \cdot m m H g$ \\
\hline \multirow{2}{*}{ Before } & 103 & 48 & 5.5 & 27.3 & 87 & 0.32 & 45.4 & 12.6 & 32.8 & 2.76 & 1.68 & $>0.059$ \\
\hline & 3 & 1 & 0.2 & 1.7 & 9 & 0.02 & 0.8 & 0.4 & 0.8 & 0.21 & 0.15 & 0.005 \\
\hline \multirow[t]{2}{*}{ After } & 112 & 64 & 6.0 & 28.5 & 100 & 0.29 & 45.7 & 12.7 & 33.0 & 1.88 & 0.84 & $>0.085$ \\
\hline & 5 & 1 & 0.2 & 1.9 & 10 & 0.02 & 0.9 & 0.3 & 1.0 & 0.12 & 0.10 & 0.008 \\
\hline$P$ & NS & $<0.001$ & $<0.005$ & NS & $<0.025$ & $<0.05$ & NS & NS & NS & $<0.001$ & $<0.001$ & $<0.025$ \\
\hline
\end{tabular}

Values are expressed as means \pm 1 SE. $n=10$ rats.

$13.3 \pm 1.7 \mathrm{nl} / \mathrm{min}$ after $\mathrm{ACH}$ infusion, while values for $(\mathrm{TF} / \mathrm{P})_{\mathrm{In}}$ decreased from an average of $1.88 \pm 0.09$ to $1.54 \pm 0.04$ (Fig. 1, Table III). The measurements of the forces affecting peritubular capillary uptake of APR revealed that $\mathrm{P}_{\mathrm{E}}, \mathrm{P}_{\mathrm{C}^{1}}$, and hence $\overline{\mathrm{P}}_{\mathrm{C}}$ increased substantially, the latter averaging $12.9 \pm 0.9$ vs. $17.2 \pm 0.7$ $\mathrm{mmHg}$. As in group 2, although the $\mathrm{P}_{1}$ also increased significantly, the increase in $\overline{\mathrm{P}}_{\mathrm{C}}$ exceeded that of $\mathrm{P}_{1}$ and yielded higher $\overline{\Delta P}_{\mathrm{C}}$ value, averaging $11.5 \pm 0.9 \mathrm{mmHg}$ before and $14.4 \pm 0.5 \mathrm{mmHg}$ after $\mathrm{ACH}$ infusion. Similar to group 1 animals, SNFF fell during $\mathrm{ACH}$, reflecting relatively greater increase in $Q_{A}$ than $S N G F R$, causing decreased $\Pi_{E}$ values during $A C H$ infusion, on average from $34.4 \pm 0.4$ to $29.7 \pm 0.9 \mathrm{mmHg}$. In association with an increase in $Q_{E}$, however, values for $\bar{\Pi}_{C}$ remained essentially constant during $\mathrm{ACH}$, as shown (38). This increase in $\mathrm{Q}_{\mathrm{E}}$ was also associated with an increase in $\mathrm{EABF}$ (mean $193 \pm 20$ vs. $266 \pm 26 \mathrm{nl} / \mathrm{min}$ ). Values for $\Pi_{1}$ were also comparable between the two periods. Consequently, $\Delta \bar{\Pi}_{\mathrm{C}}$ remained equivalent before and after $\mathrm{ACH}$ infusion, as shown. The sum of the increased $\overline{\Delta \mathrm{P}}_{\mathrm{C}}$ and similar $\overline{\Delta \Pi}_{\mathrm{C}}$ comprised a reduction in values for $\overline{\mathrm{P}}_{\mathrm{r}}$, averaging $14.2 \pm 1.3 \mathrm{mmHg}$ in the first vs. $9.7 \pm 1.4$ $\mathrm{mmHg}$ in the second study period. There was a mild but significant increase in values for $K_{\mathrm{r}}$ from an average of $0.019 \pm 0.002 \mathrm{nl} /(\mathrm{s} \cdot \mathrm{mmHg})$ before to $0.026 \pm 0.004$ $\mathrm{nl} /(\mathrm{s} \cdot \mathrm{mmHg})$ after $\mathrm{ACH}$ infusion.

\section{DISCUSSION}

In response to isoncotic plasma infusion, SNGFR increased twofold. Of the four glomerular microcirculatory indices determining SNGFR, $\overline{\Delta P}_{\mathrm{GC}}$ increased by $\sim 1 \mathrm{mmHg}$ and this slight increase is expected to contribute little to the observed marked increase in SNGFR. Statistical comparison was not possible for $K_{\mathrm{f}}$ values between the two periods, because of the filtration pressure equilibrium achieved in hydropenia. However, average minimum $K_{\mathrm{f}}$ value during hydropenia was nearly $60 \%$ that after plasma infusion, indicating that, even if $K_{f}$ did increase (by a maximum of $40 \%$ of the postplasma infusion level), the influence of this degree of increase in $K_{f}$ on the final value of SNGFR was

TABLE III

Summary of Whole Body, Glomerular, and Peritubular Capillary Hemodynamics in Group 3 Rats (ACH)

\begin{tabular}{|c|c|c|c|c|c|c|c|c|c|c|c|c|}
\hline & $\overline{\mathrm{AP}}$ & Het & $\mathrm{C}_{\mathrm{A}}$ & SNGFR & $Q_{A}$ & SNFF & $\overline{\mathrm{P}}_{\mathrm{cc}}$ & $\mathbf{P}_{\mathbf{T}}$ & $\overline{\Delta \mathrm{P}}_{\mathrm{cc}}$ & $\mathbf{R}_{\mathbf{A}}$ & $\mathbf{R}_{\mathrm{E}}$ & $K_{\mathrm{f}}$ \\
\hline & $m m H g$ & vol \% & $g / d l$ & $n l / \min$ & $n l / \min$ & & $m m H g$ & $m m H g$ & $m m H g$ & $\times 10^{10} d y_{1}$ & $\cdot \mathrm{cm}^{-5}$ & $n l /(s \cdot m m H g)$ \\
\hline \multirow[t]{2}{*}{ Before } & 106 & 51 & 5.7 & 35.0 & 111 & 0.32 & 49.2 & 13.5 & 35.6 & 2.34 & 1.60 & 0.076 \\
\hline & 2 & 2 & 0.1 & 4.5 & 17 & 0.01 & 1.4 & 1.3 & 1.5 & 0.19 & 0.20 & 0.019 \\
\hline \multirow[t]{2}{*}{ After } & 100 & 51 & 5.6 & 38.0 & 148 & 0.27 & 52.0 & 13.6 & 38.4 & 1.44 & 1.14 & 0.059 \\
\hline & 3 & 2 & 0.1 & 3.1 & 20 & 0.02 & 1.5 & 0.7 & 1.6 & 0.10 & 0.13 & 0.018 \\
\hline$P$ & $<0.025$ & NS & NS & NS & $<0.005$ & $<0.01$ & $<0.025$ & NS & NS & $<0.005$ & $<0.01$ & NS \\
\hline
\end{tabular}

Values are expressed as means \pm 1 SE. $n=7$ rats. 
TABLE II (Continued)

\begin{tabular}{|c|c|c|c|c|c|c|c|c|c|c|c|c|c|c|}
\hline$(\mathrm{TF} / \mathrm{P})_{\mathrm{In}}$ & APR & EABF & $Q_{E}$ & $\Pi_{\mathbf{E}}$ & $\bar{\Pi}_{c}$ & $\mathbf{n}_{\mathbf{l}}$ & $\overline{\Delta \Pi}_{\mathrm{c}}$ & $P_{E}$ & $\mathrm{P}_{\mathrm{c}^{1}}$ & $\overline{\mathrm{P}}_{\mathrm{c}}$ & $\mathbf{P}_{\mathbf{1}}$ & ${\overline{\Delta \mathrm{P}_{\mathrm{C}}}}$ & $\overline{\mathrm{P}}_{\mathrm{r}}$ & $K$ \\
\hline & $n l / \min$ & $n l / \min$ & $n l / \min$ & $m m H g$ & $m m H g$ & $m m H g$ & $m m H g$ & $m m H g$ & $m m H g$ & $m m H g$ & $m m H g$ & $m m H g$ & $m m H g$ & $n l /(s \cdot m m H g)$ \\
\hline 1.69 & 10.7 & 141 & 59 & 33.5 & 28.2 & 4.5 & 23.7 & 16.7 & 8.1 & 12.4 & 1.2 & 11.2 & 12.5 & 0.016 \\
\hline 0.09 & 0.7 & 14 & 8 & 2.2 & 1.7 & 0.4 & 1.5 & 0.5 & 0.6 & 0.4 & 0.2 & 0.3 & 1.5 & 0.002 \\
\hline 2.10 & 15.0 & 252 & 71 & 35.1 & 29.1 & 5.0 & 24.1 & 20.1 & 10.7 & 15.4 & 2.1 & 13.3 & 10.7 & 0.030 \\
\hline 0.11 & 1.2 & 31 & 9 & 1.9 & 1.4 & 0.5 & 1.6 & 0.7 & 0.7 & 0.6 & 0.2 & 0.5 & 1.7 & 0.006 \\
\hline$<0.01$ & $<0.001$ & $<0.001$ & $<0.01$ & NS & NS & $<0.001$ & NS & $<0.001$ & $<0.001$ & $<0.001$ & $<0.01$ & $<0.001$ & NS & $<0.025$ \\
\hline
\end{tabular}

rather small. ${ }^{6}$ Instead, glomerular plasma flow rate increased twofold after plasma infusion, and we conclude, as others have previously, that it is this increase in $Q_{A}$ that was primarily responsible for the increased SNGFR.

After plasma infusion, APR also increased. Our evaluation of various forces influencing the peritubular capillary uptake of APR revealed that there was a uniform and comparable increase in both intracapillary and interstitial hydraulic pressures after plasma expansion, so that $\overline{\Delta \mathrm{P}}_{\mathrm{C}}$ remained unaffected. SNFF de-

\footnotetext{
${ }^{6}$ On the basis of the minimum $K_{f}$ values obtained before and unique $K_{f}$ values after plasma infusion, it was possible to estimate the maximum extent to which a change in $K_{f}$, if it occurred, may have contributed to the observed increase in SNGFR. To estimate such an increase, theoretical value for SNGFR was calculated on the assumption that after plasma infusion $K_{f}$ remained at the minimum estimated level of hydropenia while the other determinants changed to the observed levels. SNGFR value thus calculated was $38.6 \mathrm{nl} / \mathrm{min}$, a value quite comparable to the observed value $(45.2 \mathrm{nl} /$ $\mathrm{min}$ ), indicating that even if a maximal increase in $K_{\mathrm{f}}$ occurred, it had little causal role in the increased SNGFR after plasma infusion. By contrast, when $Q_{A}$ was assumed not to have increased with plasma infusion, SNGFR is predicted to remain essentially at the hydropenic level $(17.8 \mathrm{nl} / \mathrm{min} \mathrm{vs}$. $23.2 \mathrm{nl} / \mathrm{min}$ ).
}

clined with plasma infusion, and oncotic pressure at the beginning of the peritubular capillary was lower after plasma infusion. However, when this value was averaged over the entire length of the peritubular capillary, a difference in $\bar{\Pi}_{C}$ between the two periods was undetectable (38). Since $\Pi_{1}$ were also comparable before and after plasma infusion, $\overline{\Delta \Pi}_{C}$ was unaffected. Therefore, as with $\overline{\Delta \mathrm{P}}_{\mathrm{C}}, \overline{\Delta \Pi}_{\mathrm{C}}$ fails to explain the observed increase in APR after plasma infusion. These assessments of the peritubular transcapillary forces led to the inevitable conclusion that the last determinant of APR, $K_{r}$, increased after plasma infusion. Indeed, values for $K_{\mathrm{r}}$ were calculated to increase significantly and substantially after plasma infusion.

In these experiments, a strong correlation was demonstrated between the level of EABF and the value of $K_{\mathrm{r}}$. In addition to this relationship between EABF vs. $K_{\mathrm{r}}$ and APR, there was a positive correlation between SNGFR and APR. Since fluid load to the proximal tubule is regarded, at least under certain circumstances $(41,42)$, to be important in modulating the rate of reabsorption by the proximal tubule, we designed the second set of experiments aiming to increase EABF while maintaining SNGFR constant. Our goal was to examine if an increase in $K_{r}$, provided it occurred, can

TABLE III (Continued)

\begin{tabular}{|c|c|c|c|c|c|c|c|c|c|c|c|c|c|c|}
\hline$(\mathrm{TF} / \mathrm{P})_{\mathrm{Ia}}$ & APR & EABF & $Q_{E}$ & $\Pi_{E}$ & $\overline{\mathbf{n}}_{\mathrm{c}}$ & $\mathbf{n}_{\mathbf{l}}$ & $\overline{\Delta \Pi}_{\mathrm{c}}$ & $\mathbf{P}_{\mathbf{E}}$ & $P_{\mathbf{C}^{1}}$ & $\overline{\mathbf{P}}_{\mathbf{c}}$ & $\mathbf{P}_{1}$ & $\overline{\Delta \mathbf{P}}_{\mathrm{c}}$ & $\overline{\mathbf{P}}_{\mathbf{r}}$ & $K_{t}$ \\
\hline & $n l / m i n$ & $n l / \min$ & $n l / \min$ & $m m H g$ & $m m H g$ & $\mathrm{mmHg}$ & $m m H g$ & $m m H g$ & $m m H g$ & $m m H g$ & $m m H g$ & $m m H g$ & $m m H g$ & $n l /(s \cdot m m H g)$ \\
\hline 1.88 & 15.4 & 193 & 76 & 34.4 & 28.4 & 2.7 & 25.7 & 16.8 & 9.1 & 12.9 & 1.5 & 11.5 & 14.2 & 0.019 \\
\hline 0.09 & 1.3 & 20 & 13 & 0.4 & 1.2 & 0.4 & 0.7 & 1.2 & 0.6 & 0.9 & 0.2 & 0.9 & 1.3 & 0.002 \\
\hline 1.54 & 13.3 & 266 & 110 & 29.7 & 27.4 & 3.3 & 24.1 & 20.7 & 13.7 & 17.2 & 2.8 & 14.4 & 9.7 & 0.026 \\
\hline 0.04 & 1.7 & 26 & 17 & 0.9 & 2.3 & 0.3 & 1.1 & 1.1 & 0.5 & 0.7 & 0.5 & 0.5 & 1.4 & 0.004 \\
\hline$<0.05$ & NS & $<0.005$ & $<0.005$ & $<0.005$ & NS & NS & NS & $<0.001$ & $<0.005$ & $<0.001$ & $<0.025$ & $<0.005$ & $<0.005$ & $<0.05$ \\
\hline
\end{tabular}


lead to an increase in APR, independently of changes in filtration rate. While our protocol proved successful in increasing EABF by maintaining the SNGFR constant, it led to a substantial increase in APR. Evaluation of forces influencing peritubular capillary uptake of APR showed that this increase in APR occurred despite unfavorable changes in the peritubular transcapillary Starling forces, i.e., increased $\overline{\Delta \mathrm{P}}_{\mathrm{C}}$ and constant $\overline{\Delta \Pi}_{\mathrm{C}}$. Again, a marked rise in reabsorption coefficient was implicated in effecting this increase in fluid reabsorption. It is noteworthy that this increase in $K_{\mathrm{r}}$ and APR during increased EABF occurred in the absence of changes in glomerular filtration.

To examine further the relationship between EABF and $K_{\mathrm{r}}$, we performed a third set of experiments, using a vasodilator, $\mathrm{ACH}$, to pharmacologically induce an increase in EABF. The ACH infusion failed to affect the value for SNGFR. Of the individual determinants of SNGFR, $\overline{\Delta P}_{G C}$ and $\Pi_{A}$ remained unchanged throughout this experiment. Instead, it was shown that the near constancy in SNGFR was largely a result of opposing influences of increased $Q_{A}$ and decreased $K_{f}$ during $\mathrm{ACH}$ infusion.

Although these changes in glomerular hemodynamics after $\mathrm{ACH}$ infusion did not produce a net change in SNGFR, they had a profound effect on the downstream peritubular capillary forces. The hydraulic pressure in the postglomerular vessels increased markedly and greatly exceeded the concomitant increase in $P_{1}$. Therefore, as in the blood-infused animals, $\overline{\Delta \mathrm{P}}_{\mathrm{C}}$ increased markedly. While the decrease in $K_{\mathrm{f}}$ and the profound increase in $Q_{A}$ during $A C H$ infusion led to a reduction in immediate postglomerular plasma protein concentration, the higher $Q_{E}$ resulted in comparable values for average intracapillary oncotic pressures before and during $\mathrm{ACH}$ infusion (38). Since $\Pi_{1}$ also remained virtually constant, $\overline{\Delta \Pi}_{\mathrm{C}}$, values were unaffected by $\mathrm{ACH}$. The observed increase in $\overline{\Delta \mathrm{P}}_{\mathrm{C}}$ and constancy in $\overline{\Delta \Pi}_{C}$ during $A C H$ infusion are expected to favor a decline in APR. Yet, the measured values for APR were similar before and after ACH infusion, again implicating an increase of $K_{\mathrm{r}}$ during $\mathrm{ACH}$-induced increase in EABF. ${ }^{7}$ Overall, as shown in Fig. 2, a strong positive correlation between $\mathrm{EABF}$ and $K_{\mathrm{r}}$ was

\footnotetext{
${ }^{7}$ Divergent effects of $\mathrm{ACH}$ upon $K_{\mathrm{f}}$ in the glomerular capillary bed and $K_{r}$ in the peritubular capillary bed may be related to anatomical differences between these two vascular beds. The decrease in $K_{\mathrm{f}}$ value during $\mathrm{ACH}$ infusion, at least numerically, may be mediated through the mesangial cells in the glomerulus. The apparent absence of their response in the peritubular capillary may be related to lack of these contractile elements in the postglomerular circulation.
}

demonstrated in all three groups studied, where EABF changes were induced by different experimental maneuvers.

Several previous studies have shown that changes in $K_{r}$ can occur under various circumstances and are capable of influencing APR $(3,16,23,25,26,43)$. These changes in $K_{\mathrm{r}}$ were usually observed in association with variation in renal blood flow. ${ }^{8}$ Mertz et al. (23) have recently shown that secretin-induced renal vasodilation and increase in renal blood flow was accompanied by a marked increase in $K_{\mathrm{r}}$. In our recent study, progressive increases in the reabsorption rate and renal blood flow in growing rats were shown to accompany a rise in $K_{r}$ (25). In another micropuncture study (26), renal nerve stimulation in rats was found to depress $K_{\mathrm{r}}$ in association with a tendency of EABF to fall. A study of whole kidney clearance of macromolecules in dogs by Whiteside and Silverman (43) concluded that, at least for a certain range of renal blood flow, the peritubular capillary permeability coefficient changes in strong relation with postglomerular blood flow.

Since $K_{\mathrm{r}}$ is a product of both the permeability of the capillary wall to water and the surface area available for fluid exchange, changes in either or both of these terms can account for the observed EABF-dependence of $K_{r}$. In this regard, studies in vascular systems of other organs demonstrated that blood flow rate is an important determinant of capillary surface area. For example, in skeletal muscle, the increase in blood flow associated with exercise accompanies increasing number of open vascular channels (46), whereas nerve stimulation decreases the number of these channels, thereby affecting the blood flow and the rate of transfer of solutes and water (46). Although most of such studies emphasize the number of open capillary channels available for fluid transfer as an effector mechanism for blood flow dependency of permeability coefficient, another possibility exists, namely that the diameter of the already patent vascular channels may vary in accordance with the level of inflow. In this respect, Koch Jensen and Steven $(47,48)$ demonstrated by a morphometric method that the diameter of the peritubular capillary in renal superficial cortex can indeed change in response

\footnotetext{
${ }^{8}$ On the basis of previous $(1,15)$ and present experimental data, it seems clear that other factors must also be contributory in determining the level of $K_{r}$. For instance, in other vascular systems $(44,45)$, intracapillary pressure also appears to affect permeability coefficient or surface area of the capillary. Available data further indicate that the relationship between renal blood flow and $K_{\mathrm{r}}$ may be nonlinear, since increases in blood flow from mildly to modestly high level was not accompanied by detectable changes in $K_{\mathrm{r}}(1,15)$.
} 


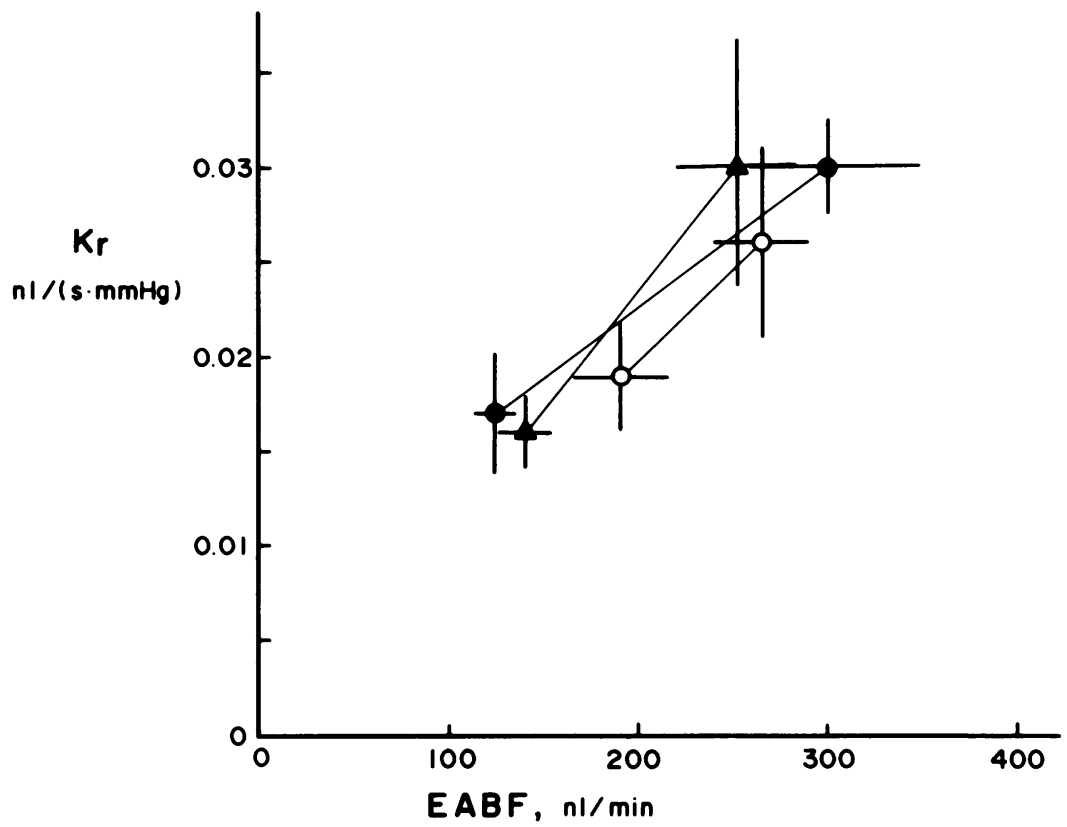

FIGURE 2 Summary of the data for EABF and $K_{\mathrm{r}}$ obtained in the three groups of rats studied. Data obtained within the same group of animals are connected by straight lines. Plasma infusion $(\mathbf{O})$; blood infusion ( $\mathbf{\Delta})$; ACH infusion (O).

to certain experimental maneuvers. Thus, it is possible that variation in the renal blood flow can affect the peritubular capillary coefficient by passively changing the surface area available for reabsorption through opening of new channels, expanding already patent ones, or a combination thereof. It is also conceivable that when such expansion of capillaries occurs, the permeability of the capillary wall to water also increases to some extent. In all three groups of animals examined in the present study, the resistances of the peritubular capillary to axial flow decreased uniformly; on average, from $0.53 \pm 0.09$ to $0.23 \pm 0.04 \times 10^{10}$ dyn $\cdot \mathrm{s} \cdot \mathrm{cm}^{-5}$ after plasma infusion; $0.52 \pm 0.07$ to $0.33 \pm 0.05 \times 10^{10} \mathrm{dyn} \cdot \mathrm{s} \cdot \mathrm{cm}^{-5}$ after blood infusion; and $0.33 \pm 0.04$ to $0.21 \pm 0.03 \times 10^{10} \mathrm{dyn} \cdot \mathrm{s} \cdot \mathrm{cm}^{-5}$ during $\mathrm{ACH}$ infusion. This uniform decline in resistances suggests that the observed increase in $K_{\mathrm{r}}$ in each of these instances was, at least in part, related to an increase in capillary diameter and/or to recruitment of new capillary channels, and hence, surface area available for reabsorption.

It should be recognized that our observations are also consistent with the possibility that the prevailing circulatory volume status may, through activation (or deactivation) of systemic and/or local factors, directly influence $K_{r}$. Volume expansion or administration of vasodilators may, via increased circulatory vasodilative substances (or decreased vasoconstrictive substances), affect both the renal blood flow and $K_{\mathrm{r}}$.

The observed blood flow dependence of APR is reminiscent of plasma flow dependence of GFR in this species of animals and lead us to consider that this EABF dependence of $K_{\mathrm{r}}$ may play an important role in the so-called glomerulotubular balance, a term used to describe changes in GFR that are accompanied by directionally similar and roughly proportional changes in the rate of fluid reabsorbed by the proximal tubule. Fig. 3 illustrates this point. The open and filled circles in the bottom left corner of the figure depict typical values for SNGFR and APR in normal rats. The ratio between APR and SNGFR defines fractional proximal reabsorption. Any point falling on the dashed straight line, therefore, indicates maintenance of perfect glomerulotubular balance. In the first group of animals, we have shown, as have others $(36,49,50)$, that, after isoncotic plasma infusion, increase in SNGFR occurs, owing primarily to increased plasma flow rate, as indicated by the rightward arrow. Concomitantly, the rise in plasma flow brought about an increase in EABF and the associated increase in $K_{\mathrm{r}}$, which in turn led to an increase in APR, indicated by the upgoing arrow directed toward (but not reaching) the line of perfect glomerulotubular balance. In the second group of animals, the selective increase in EABF with high Hct 
blood infusion caused an increase in APR without changes in SNGFR, as indicated by the left upgoing arrow, i.e., away from the line of perfect glomerulotubular balance. We believe that under physiologic and pathophysiologic circumstances SNGFR and APR change in a manner best described by a point falling between the two experimentally induced extremes shown in Fig. 3, i.e., more perfect glomerulotubular balance (interrupted lines). This is because physiologic variation in renal blood flow is not a consequence of changes in the flow of either plasma or erythrocytes alone, but is instead a combination of the two.

Thus, this blood flow dependence of $K_{\mathrm{r}}$ and APR, together with plasma flow dependence of GFR, provide a physiologic basis of glomerulotubular balance, particularly when GFR varies along with alterations in renal blood flow. On the other hand, when changes in GFR occur in the absence of changes in renal blood flow, peritubular capillary physical forces become important in the preservation of glomerulotubular balance, i.e., via filtration fraction and oncotic pressure. Clearly, our observations do not negate the importance of luminal or epithelial factors $(41,42,51,52)$ that might also contribute to the phenomenon of glomerulotubular balance. Instead, it is more likely that multiple mechanisms are necessary for the effective achievement of

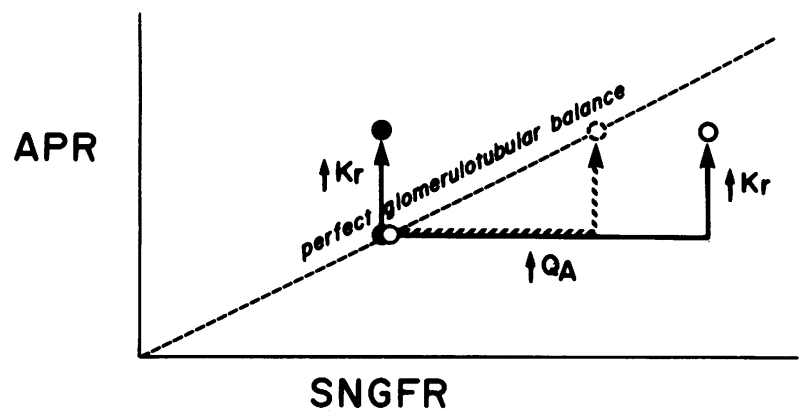

Figure 3 Schematic presentation of the proposed mechanism for the preservation of glomerulotubular balance when SNGFR varies with renal blood flow. The two arrows with solid lines depict changes during two extreme experimental perturbations (plasma infusion [O] on the right and high Het blood infusion [0] on the left). In contrast to these two experimental circumstances, where glomerulotubular balance is disrupted owing to preferential increase in the flow of plasma or erythrocyte component, it is predicted that physiological circumstances are characterized by a more perfect balance (interrupted line). Thus, GFR changes in accord with $Q_{A}$, while greater changes in $K_{r}$ and APR occur than are expected from the degree of increase in plasma flow alone. It is the simultaneous increase in the flow of erythrocytes component that augments these changes in $K_{r}$ and APR. glomerulotubular balance, with the combination of physical forces and $K_{\mathrm{r}}$ being an integral component.

\section{ACKNOWLEDGMENTS}

We would like to express our appreciation to Miss Sheila $L$. Ellis for her expert technical assistance.

This work was supported, in part, by National Institutes of Health grants AM 27853 and AM 16392.

\section{REFERENCES}

1. Ichikawa, I., and B. M. Brenner. 1979. Mechanism of inhibition of proximal tubule fluid reabsorption after exposure of the rat kidney to the physical effects of expansion of extracellular fluid volume. J. Clin. Invest. 64:1466-1474.

2. Blantz, R. C., and B. J. Tucker. 1975. Determinants of peritubular capillary fluid uptake in hydropenia and saline and plasma expansion. Am. J. Physiol. 228:19271935.

3. Tucker, B. J., and R. C. Blantz. 1978. Determinants of proximal tubular reabsorption as mechanisms of glomerulotubular balance. Am. J. Physiol. 235:F142-F150.

4. Brenner, B. M., K. H. Falchuk, R. I. Keimowitz, and R. W. Berliner. 1969. The relationship between peritubular capillary protein concentration and fluid reabsorption by the renal proximal tubule. J. Clin. Invest. 48:1519-1531.

5. Maddox, D. A., C. M. Bennett, W. M. Deen, R. J. Glassock, D. Knutson, and B. M. Brenner. 1975. Control of proximal tubule fluid reabsorption in experimental glomerulonephritis. J. Clin. Invest. 55:1315-1325.

6. Bank, N., H. S. Aynedjian, and T. Wada. 1972. Effect of peritubular capillary perfusion rate on proximal sodium reabsorption. Kidney Int. 1:397-405.

7. Martino, J. A., and L. E. Earley. 1967. Demonstration of a role of physical factors as determinants of the natriuretic response to volume expansion. J. Clin. Invest. 46:1963-1978.

8. Daugharty, T. M., I. F. Ueki, D. P. Nicholas, and B. M. Brenner. 1972. Comparative renal effects of isoncotic and colloid-free volume expansion in the rat. Am. J. Physiol. 222:225-235.

9. Lewy, J. E., and E. E. Windhager. 1968. Peritubular control of proximal tubular fluid reabsorption in the rat kidney. Am. J. Physiol. 214:943-954.

10. Spitzer, A., and E. E. Windhager. 1970. Effect of peritubular oncotic pressure changes on proximal tubular fluid reabsorption. Am. J. Physiol. 218:1188-1193.

11. Brenner, B. M., and J. L. Troy. 1971. Postglomerular vascular protein concentration. Evidence for a causal role in governing fluid reabsorption and glomerulotubular balance by the renal proximal tubule. J. Clin. Invest. 50:336-349.

12. Falchuk, K. H., B. M. Brenner, M. Tadokoro, and R. W. Berliner. 1971. Oncotic and hydrostatic pressures in peritubular capillaries and fluid reabsorption by proximal tubule. Am. J. Physiol. 220:1427-1433.

13. Ott, C. E., J. A. Haas, J.-L. Cuche, and F. G. Knox. 1975. Effect of increased peritubular protein concentration on proximal tubule reabsorption in the presence and ab- 
sence of extracellular volume expansion. J. Clin. Invest. 55:612-620.

14. Quinn, M. D., and D. J. Marsh. 1979. Peritubular capillary control of proximal tubule reabsorption in the rat. Am. J. Physiol. 236:F478-F487.

15. Ichikawa, I., and B. M. Brenner. 1980. Importance of efferent arteriolar vascular tone in regulation of proximal tubule fluid reabsorption and glomerulotubular balance in the rat. J. Clin. Invest. 65:1192-1201.

16. Ichikawa, I., J. R. Hoyer, M. W. Seiler, and B. M. Brenner. 1982. Mechanism of glomerulotubular balance in the setting of heterogenous glomerular injury. Preservation of a close functional linkage between individual nephrons and surrounding microvasculature. J. Clin. Invest. 69:185-198.

17. Ichikawa, I., H. G. Rennke, J. R. Hoyer, K. F. Badr, N. Schor, J. L. Troy, C. P. Lechene, and B. M. Brenner. 1983. Role for intrarenal mechanisms in the impaired salt excretion of experimental nephrotic syndrome. $J$. Clin. Invest. 71:91-103.

18. Brenner, B. M., J. L. Troy, and T. M. Daugharty. 1971. On the mechanism of inhibition in fluid reabsorption by the renal proximal tubule of the volume-expanded rat. J. Clin. Invest. 50:1596-1602.

19. Steiner, R. W., B. J. Tucker, and R. C. Blantz. 1979. Glomerular hemodynamics in rats with chronic sodium depletion. Effect of Saralasin. J. Clin. Invest. 64:503512.

20. Pelayo, J. C., M. G. Ziegler, P. A. Jose, and R. C. Blantz. 1983. Renal denervation in the rat: analysis of glomerular and proximal tubular function. Am. J. Physiol. 244:F70-F77.

21. Myers, B. D., W. M. Deen, and B. M. Brenner. 1975. Effects of norepinephrine and angiotensin II on the determinants of glomerular ultrafiltration and proximal tubule fluid reabsorption in the rat. Circ. Res. 37:101110.

22. Baylis, C., W. M. Deen, B. D. Myers, and B. M. Brenner. 1976. Effects of some vasodilator drugs on transcapillary fluid exchange in renal cortex. Am. J. Physiol. 230:11481158.

23. Mertz, J. I., J. A. Haas, T. J. Berndt, J. C. Burnett, Jr., and F. G. Knox. 1983. Effects of secretin on peritubular capillary physical factors and proximal fluid reabsorption in the rat. J. Clin. Invest. 72:622-625.

24. Mertz, J. I., J. A. Haas, T. J. Berndt, J. C. Burnett, and F. G. Knox. 1983. Effects of bradykinin on proximal tubule fluid reabsorption and peritubular capillary physical factors. Clin. Res. 31:437a. (Abstr.)

25. Kon, V., M. L. Hughes, and I. Ichikawa. 1983. Physiologic basis for the maintenance of glomerulo tubular balance in young growing rats. Kidney Int. In press.

26. Kon, V., and I. Ichikawa. 1983. Effector loci for renal nerve control of cortical microcirculation. Am. J. Physiol. 245:F545-F553.

27. Ichikawa, I., M. A. Pfeffer, J. M. Pfeffer, and B. M. Brenner. 1983. Role of angiotensin II in altered nephron function in congestive heart failure. Clin. Res. 31:515a. (Abstr.)

28. Wolgast, M., E. Persson, J. Schnermann, H. Ulfendahl, and P. Wunderlich. 1973. Colloid osmotic pressure of the subcapsular interstitial fluid of rat kidneys during hydropenia and volume expansion. Pfuegers Arch. Eur. J. Physiol. 340:123-131.
29. Bell, R. D., W. L. Parry, and W. G. Grundy. 1973. Renal lymph sodium and potassium concentrations following renal vasodilatation. Proc. Soc. Exp. Biol. Med. 143:499501 .

30. Källskog, Ö., and M. Wolgast. 1973. Driving forces over the peritubular capillary membrane in the rat kidney during antidiuresis and saline expansion. Acta Physiol. Scand. 89:116-125.

31. O’Morchoe, C. C. C., P. J. O'Morchoe, and E. J. Donati. 1975. Comparison of hilar and capsular renal lymph. Am. J. Physiol. 229:416-421.

32. Vurek, G. G., and S. E. Pegram. 1966. Fluorometric method for the determination of nanogram quantities of inulin. Anal. Biochem. 16:409-419.

33. Führ, J., J. Kazmarczyk, and C. D. Kruttgen. 1955. Eine einfache colorimetrische Methode zur Inulinbestimmung für Nieren-Clearance-Untersuchungen bei Stoffwechselgesunden und Diabetikern. Klin. Wochenschr. 33:729-730.

34. Viets, J. W., W. M. Deen, J. L. Troy, and B. M. Brenner. 1978. Determination of serum protein concentration in nanoliter blood samples using fluorescamine or $o$ ophthalaldehyde. Anal. Biochem. 88:513-521.

35. Lowry, O. H., N. J. Rosebrough, A. L. Farr, and R. J. Randall. 1951. Protein measurements with the Folin phenol reagent. J. Biol. Chem. 193:265-275.

36. Ichikawa, I., D. A. Maddox, M. G. Cogan, and B. M. Brenner. 1978. Dynamics of glomerular ultrafiltration in euvolemic Munich-Wistar rats. Renal Physiol. 1:121131.

37. Deen, W. M., J. L. Troy, C. R. Robertson, and B. M. Brenner. 1973. Dynamics of glomerular ultrafiltration in the rat. IV. Determination of the ultrafiltration coefficient. J. Clin. Invest. 52:1500-1508.

38. Deen, W. M., C. R. Robertson, and B. M. Brenner. 1973. A model of peritubular capillary control of isotonic fluid reabsorption by the renal proximal tubule. Biophys. J. 13:340-358.

39. Hargens, A. R., B. J. Tucker, and R. C. Blantz. 1977. Renal lymph protein in the rat. Am. J. Physiol. 233:F269F273.

40. Deen, W. M., I. F. Ueki, and B. M. Brenner. 1976. Permeability of renal peritubular capillaries to neutral dextrans and endogenous albumin. Am. J. Physiol. 231:283291.

41. Haberle, D. A., T. T. Shiigai, G. Maier, H. Schiff, and J. M. Davis. 1981. Dependency of proximal tubular fluid transport on the load of glomerular filtrate. Kidney Int. 20:18-28.

42. Kiil, F. 1982. Mechanism of glomerulotubular balance: the whole kidney approach. Renal Physiol. 5:209-221.

43. Whiteside, C., and M. Silverman. 1983. Postglomerular capillary permeability determination in dogs. Kidney Int. 23:249a. (Abstr.).

44. Mason, J. C., F. E. Curry, and C. C. Michel. 1977. The effects of proteins upon the filtration coefficient of individually perfused frog mesenteric capillaries. Microvasc. Res. 13:185-202.

45. Shepherd, J. T., and P. M. Vanhoutte. 1979. The Human Cardiovascular System. Facts and Concepts. Raven Press. New York. 82-83.

46. Renkin, E. M. 1978. Nutritive and shunt flow. In Microcirculation II. G. Kaley and B. M. Altura, editors. University Park Press, Baltimore. 351-369. 
47. Koch Jensen, P., and K. Steven. 1979. Influence of intratubular pressure on proximal tubular compliance and capillary diameter in the rat kidney. Pfluegers Arch. Eur. J. Physiol. 382:179-187.

48. Koch Jensen, P., and K. Steven. 1977. Angiotensin IIinduced reduction of peritubular capillary diameter in the rat kidney. Pfluegers Arch. Eur. J. Physiol. 371:245250.

49. Brenner, B. M., J. L. Troy, T. M. Daugharty, W. M. Deen, and C. R. Robertson. 1972. Dynamics of glomerular ultrafiltration in the rat. II. Plasma-flow dependence of GFR. Am. J. Physiol. 223:1184-1190.

50. Robertson, C. R., W. M. Deen, J. L. Troy, and B. M.
Brenner. 1972. Dynamics of glomerular ultrafiltration in the rat III. Hemodynamics and autoregulation. Am. J. Physiol. 223:1191-1200.

51. Sasaki, S., C. A. Berry, and F. C. Rector, Jr. 1982. Effect of luminal and peritubular $\mathrm{HCO}_{3}^{-}$concentrations and $\mathrm{PCO}_{2}$ on $\mathrm{HCO}_{3}^{-}$reabsorption in rabbit proximal convoluted tubules perfused in vitro. J. Clin. Invest. 70:639649.

52. Schaffer, J. A., S. L. Troutman, M. L. Watkins, and T. E. Andreoli. 1981. Flow dependence of fluid transport in the isolated superficial pars recta: evidence that osmotic disequilibrium between external solutions drives isotonic fluid absorption. Kidney Int. 20:588-597. 